\title{
Sociodemographic profile and quality of life of caregivers of elderly people with dementia
}

\author{
Raquel Santos de Queiroz' \\ Alessandra Conceição Leite Funchal Camacho' \\ Jonas Lírio Gurgel' \\ Cíntia Raquel da Costa de Assis' \\ Lucimere Maria dos Santos ${ }^{1}$ \\ Mauro Leonardo Salvador Caldeira dos Santos ${ }^{1}$
}

\section{Abstract}

Objective: To analyze the association between sociodemographic profile, health profile and the quality of life of caregivers of elderly people diagnosed with dementia. Method: A cross-sectional study was carried out in a geriatric outpatient unit with 35 elderly caregivers diagnosed with dementia. A socio-demographic and health characterization form was used as well as the WHOQOL-bref scale. To verify the association of the variables, the Spearman or Pearson correlation tests were applied, according to the normality of the data. Results: A moderate association between caregiver age and quality of life was found, as well as between total time of care and quality of life, which reveals that the care provided to the elderly with dementia has repercussions on the quality of life. The domains of the WHOQOL-bref with the highest means were Social and Physical Relations, and those with lower mean values were Psychological and Environmental. Conclusion: The identification of conditions that influence the quality of life of caregivers of elderly people with dementia allows actions to promote, protect and recover the health and well-being of those who provide care to be established, so that this care is both for themselves and for the elderly.
Keywords: Caregivers.

Dementia. Nursing. Elderly. Quality of Life.

Universidade Federal Fluminense, Escola de Enfermagem Aurora de Afonso Costa, Programa de Pósgraduação em Ciências do Cuidado em Saúde. Niterói, Rio de Janeiro, Brasil. 


\section{INTRODUCTION}

Dementia is a set of clinical signs and symptoms characterized by memory, language, behavioral difficulties which has consequences in the planning and performance of activities of daily living.

There are several types of dementia, of which Alzheimer's Disease is the most prevalent among the elderly (60-70\%), followed by vascular dementia, Lewy body dementia and frontotemporal dementias ${ }^{2}$.

Around 24 million elderly people had some type of dementia in 2001, a figure that is expected to double every 20 years, to 42 million in 2020 and 81 million in $2040^{3}$.

As it is a chronic and limiting disease, elderly persons experience difficulties in carrying out their daily activities, making them increasingly dependent on additional care. A study conducted in North America has found that people with dementia need at least 8.5 hours of daily care, with care ranging from 17.5 to 41.5 hours daily in moderate to severe conditions ${ }^{4}$.

This care is often provided by caregivers, who represent the link between the elderly, the family and health services. A caregiver is defined as the person who is responsible for caring for an elderly person who depends on assistance from the health services for their hygiene, medication, domestic and social activities, regardless of the absence or presence of a family bond or remuneration ${ }^{5}$.

In view of the incapacitating conditions caused by dementia, caregivers become part of the family context of the elderly person, assuming responsibility for activities that were previously performed by the elderly individual themselves, such as daily care, home care, account management and basic care activities ${ }^{6}$.

The execution of administrative and care activities are factors that impair the quality of life of caregivers. This is defined as a person's perception of the position of their life relative to the cultural values of the place where they live, in addition to their goals, expectations, standards and concerns?
The hours spent on care, the lack of information and support, the degree of fatigue and the day to day activities performed are defined as some factors that contribute to intensifying caregiver burden ${ }^{8}$.

Caregivers of elderly persons diagnosed with dementia are more likely to develop psychiatric symptoms, physical, social and financial problems, hypertension, arterial, thyroid, osteoporosis, digestive and respiratory disorders, anxiety, insomnia and depression?.

Health problems arise from the impact of tasks performed by caregivers, often without proper guidance or support from others, and the accumulation of activities affects their own personal lives ${ }^{8}$.

Considering the increase in the aging population and the diversity in care relationships, the need to identify and understand factors related to the quality of life of caregivers of elderly people with dementia should be highlighted. The present study is therefore based on the following question: what is the association between socio-demographic profile and characteristics and the quality of life of caregivers of elderly persons with dementia?

The objective of the study was to analyze the association between the sociodemographic profile, characteristics of care and quality of life of caregivers of elderly persons diagnosed with dementia.

\section{METHOD}

A cross-sectional quantitative study was conducted at a geriatric outpatient clinic for elderly care linked to a public university, located in the city of Niterói in the state of Rio de Janeiro.

The inclusion criteria adopted were that the care recipient and their caregiver receive care from the Health Care Center for the Elderly and their Caregivers; that the caregiver is aged over 18 years old; is a formal and/or informal caregiver for an elderly person with dementia; has been the primary caregiver for at least six months. The exclusion criteria were sporadic attendance at the Health Care Center for the Elderly and their Caregivers and the 
presence of a communication disturbance that made it difficult to perform the tests.

The research population was caregivers of elderly people with dementia receiving care through the outpatient nursing clinic and was composed of 81 active caregivers from the program. Of these, 22 caregivers reported that they were unavailable for nursing appointments, 14 caregivers were not located through their registered phone numbers, and ten caregivers did not meet the inclusion criteria.

The sample size was calculated by the Gpower 3.1 software package to achieve a power of 0.8 and a significance level of 0.05 . The sample consisted of all caregivers of elderly people with dementia who participated in the nursing consultations and met the established criteria, resulting in a total of 35 participants.

The data collection period was from November 2016 to April 2017. The technique used to collect data from the caregivers of elderly people with dementia was a structured interview of exploratory character performed during the nursing appointment, using an instrument created and pre-tested by the researchers to record the sociodemographic and health characteristics of the caregivers.

For the characterization of sociodemographic and health status, the following data was recorded: age; caregiver category (formal/informal); gender; schooling; marital status; professional activity; family income; cohabitation with the elderly; division of care; degree of kinship with the elderly; health problems; continuous use of medication and psychotherapy.

The WHOQOL-bref scale was used to measure quality of life. This scale has 26 questions, with Likert-type scales from zero to five. The questions are divided into four domains (Physical, Environmental, Psychological and Social Relationships). Their results initially varied from four to 20 and were then converted to a scale of 0 to $100 \%$. In this way, the higher the value, the better was the quality of life.
The instruments were completed after the conclusion of the nursing appointment, through invitation, reading and a signing of a Free and Informed Consent Form. The interview was held in a reserved location and the participants' anonymity was preserved.

For the analysis of the data, a spreadsheet was constructed with double entry of the data which was then validated for comparisons. The variables gender, age, category, total time providing care, division of care and cohabitation with the elderly person were then imported into the statistical software to perform the statistical tests.

For all tests, a level of significance of $p \leq 0.05$ was adopted. To analyze the normality of the data the Shapiro-Wilk test was applied. The variables gender, caregiver category, division of care and cohabitation were presented in comparative forms in relation to the quality of life scores. For the association between the variables age and quality of life, the Pearson Correlation Test (data with normal distribution) was used and to associate the total time providing care and quality of life the Spearman's Correlation Test (non-normal distributed data) was used. Both tests allow the relationship between two quantitative variables to be established.

The study was approved by the Research Ethics Committee of the Hospital Universitário Antônio Pedro (HUAP) of the Universidade Federal Fluminense (UFF) under number 1.740.880, in accordance with Resolution $n^{\circ} 466 / 2012$ of the National Health Council. Two copies of a Free and Informed Consent Form were signed by the participants.

\section{RESULTS}

The sample of the present study consisted of 35 caregivers of elderly people with dementia. Table 1 shows the descriptive sociodemographic analysis of the sample and Table 2 illustrates the characteristics of the type of care provided by caregivers. 
Table 1. Sociodemographic profile of sample. Niterói, Rio de Janeiro, 2017.

\begin{tabular}{|c|c|}
\hline Variable & $\mathrm{n}(\%)$ \\
\hline \multicolumn{2}{|l|}{ Gender } \\
\hline Female & $32(91.4)$ \\
\hline Male & $3(8.6)$ \\
\hline \multicolumn{2}{|l|}{ Age years) } \\
\hline$<60$ & $19(54.3)$ \\
\hline$\geq 60$ & $16(45.7)$ \\
\hline \multicolumn{2}{|c|}{ Marital status } \\
\hline Unmarried & $7(20.0)$ \\
\hline Married & $23(65.7)$ \\
\hline Divorced & $4(11.4)$ \\
\hline Widower & $1(2.8)$ \\
\hline \multicolumn{2}{|c|}{ Schooling (years) } \\
\hline 0 & $1(2.8)$ \\
\hline $1-4$ & $2(5.7)$ \\
\hline $5-9$ & $4(11.4)$ \\
\hline $10-12$ & $20(57.2)$ \\
\hline$\geq 12$ & $8(22.9)$ \\
\hline \multicolumn{2}{|c|}{ Income (minimum salary)* } \\
\hline 1 to 3 & $22(62.8)$ \\
\hline 4 to 6 & $12(34.3)$ \\
\hline$\geq 7$ & $1(2.8)$ \\
\hline \multicolumn{2}{|c|}{ Professional activity } \\
\hline Yes & $14(40.0)$ \\
\hline No & $21(60.0)$ \\
\hline
\end{tabular}

*2017 minimum salary: $\mathrm{R} \$ 937.00$.

Table 2. Characteristics of care provided by caregivers of elderly persons with dementia. Niterói, Rio de Janeiro, 2017.

\begin{tabular}{ll}
\hline Variable & $\mathrm{n}(\%)$ \\
\hline Type of caregiver & $27(77.1)$ \\
Informal/Family member & $8(22.9)$ \\
Formal & $9(20.0)$ \\
\hline Relationship & $14(20.0)$ \\
Spouse & $2(58.0)$ \\
Son/daughter & $1(7.0)$ \\
Brother/sister & $1(3.0)$ \\
Grandson/granddaughter & \\
Nephew/niece & $7(20.0)$ \\
\hline Daily workload (hours) & $28(80.0)$ \\
$4-7$ & \\
$\geq 8$ & $19(54.3)$ \\
Division of care & $16(45.7)$ \\
Yes & to be continued
\end{tabular}


Continuation of Table 2

\begin{tabular}{ll}
\hline Variable & $\mathrm{n}(\%)$ \\
\hline Lives with elderly person & \\
Yes & $19(54.3)$ \\
No & $16(45.7)$ \\
\hline Total time spent caring (years) & \\
$\leq 4$ & $22(62.8)$ \\
$\geq 5$ & $13(37.2)$ \\
\hline
\end{tabular}

In terms of health profile, $85.7 \%$ of the caregivers had a chronic health problem (self-reported variable), with the most frequent illnesses being: spinal problems (33.3\%); systemic arterial hypertension $(28.2 \%)$; diabetes mellitus (12.8\%) and depression (7.7\%). Less frequent illnesses $(2.6 \%)$ were: hypothyroidism; asthma; endometriosis; respiratory allergies; arthrosis and heart disease.

Regarding the continuous use of medication, $12.3 \%$ did not use medications and $65.7 \%$ used some medication. Among the most frequent drug classes were analgesics, hypoglycemic agents and antidepressants.

About $34.0 \%$ of caregivers stated that they undergone psychotherapy, while $65.7 \%$ said they had never undergone any kind of psychotherapeutic treatment.

The results in relation to quality of life, measured by the WHOQOL-bref scale, were stratified according to the four domains, as shown in Table 3, which describes a score from 0 to 100 in percentage values.

Table 3. Scores relating to the domains and facets of the WHOQOL-bref of the participants. Niterói, Rio de Janeiro, 2017.

\begin{tabular}{ll}
\hline Domain/Facet & Score $(\%)$ \\
\hline Physical & 62.2 \\
\hline Pain and discomfort & 65.7 \\
Energy and fatigue & 65.7 \\
Sleep and rest & 50.0 \\
Mobility & 81.4 \\
Daily activities & 65.0 \\
Medication dependence & 47.9 \\
Work capacity & 60.0 \\
Positive feelings & 40.7 \\
Psychological & 61.1 \\
Self esteem & 69.3 \\
Negative feelings & 63.6 \\
Spirituality/religion/beliefs & 58.6 \\
\hline Social relationships & 63.1 \\
\hline Personal relationships & 62.9 \\
Support and social support & 68.6 \\
Sexual activity & 57.9 \\
\hline
\end{tabular}


Continuation of Table 3

\begin{tabular}{ll}
\hline Environment & 51.8 \\
\hline Physical security and protection & 52.9 \\
Home environment & 67.9 \\
Financial resources & 42.9 \\
Health care & 40.0 \\
New information/skills & 63.4 \\
Recreation and leisure & 32.1 \\
Physical environment & 65.7 \\
Transport & 46.4 \\
\hline Self-assessment of quality of life & 61.8 \\
\hline General quality of life & 58.8 \\
\hline
\end{tabular}

From the results presented in Table 4, it can be seen that of the four domains, the two with the highest scores are Social Relationships (63.1\%) and Physical (62.2\%). Psychological (61.1\%) and Environment $(51.8 \%)$, meanwhile, had the lowest scores.

Regarding the self-assessment of quality of life, based on the questions How would you evaluate your quality of life? and How satisfied are you with your health?, an average of $61.8 \%$ was obtained. In the first question, the response neither good nor bad (48.6\%) predominated, and in the second the satisfied response was the most frequent $(42.9 \%)$. The majority of participants assessed their quality of life as fair, since there were few cases of complete dissatisfaction or complete satisfaction.

In the Physical domain, mobility was the highest rated facet, with 18 of the 35 participants (51.4\%) reporting that their locomotion capacity was very good. The worst rated question related to physical pain, with $13(37.1 \%)$ saying that pain prevented them from carrying out activities to some degree.

In the Psychological domain, the worst evaluated question was in relation to negative feelings, where $16(45.7 \%)$ of the participants reported that they sometimes have feelings such as bad moods, despair, anxiety and depression, and seven (20.0\%) saying that they often have negative feelings. The best evaluated question was physical appearance, with 15 $(42.8 \%)$ stated that they completely accepted their physical appearance.
In the Social Relationships domain, the question on sex life had the lowest evaluation, with 11 (31.4\%) saying that they were neither satisfied nor dissatisfied. The support received from friends received the highest evaluation, with 20 (57.1\%) individuals answering they were satisfied.

In the Environment domain the lowest evaluation was related to recreation and leisure, with 13 (37.1\%) of the participants reporting that they had very little opportunity for leisure. Residence was the best evaluated question, with 17 (48.5\%) answering that they were satisfied with the conditions of the place where they lived.

Table 4 indicates the overall quality of life score among the evaluated categories.

The results show that female caregivers had better quality of life scores than men, as did older persons who had provided care for longer. There was no difference between the categories of caregivers, and a minimum difference between those who divided care and those who did not or did not cohabit with the elderly.

The Pearson's correlation test was used to verify the association between age and quality of life, while Spearman's correlation test was used to verify the association between total time of care and quality of life and family income and quality of life, as shown in Table 5. 
Table 4. General quality of life score in categories. Niterói, Rio de Janeiro, 2017.

\begin{tabular}{ll}
\hline Variables & Overall quality of life score $(\%)$ \\
\hline Gender & 84.4 \\
Female & 80.0 \\
Male & \\
\hline Age & 82.5 \\
$<60$ & 85.0 \\
$\geq 60$ & \\
Category & 83.7 \\
Informal/family & 83.7 \\
Formal & \\
\hline Time spent as caregiver (years) & 80.6 \\
$<5$ & 89.3 \\
$\geq 5$ & \\
\hline Division of care & 85.0 \\
Yes & 81.8 \\
No & \\
\hline Cohabits with elderly person & 84.4 \\
Yes & 85.2 \\
No &
\end{tabular}

Table 5. Correlation tests between quality of life, age, total time of care and family income. Niterói, Rio de Janeiro, 2017.

\begin{tabular}{lll}
\hline Variable & \multicolumn{2}{l}{ Quality of Life } \\
\cline { 2 - 3 } & $\mathrm{r}$ & $p$ \\
\hline Age of caregiver & $0.399^{* *}$ & $0.018^{*}$ \\
\hline Time providing care & $0.395^{* * *}$ & $0.019^{*}$ \\
\hline Family income & $-0.38^{* * *}$ & 0.828 \\
\hline
\end{tabular}

*Correlation significant at level of 0.05 (bilateral); **Pearson's correlation test; ***Spearman's correlation test.

Through the analysis of the results it can be seen that there is a moderate and significant association between the age of the caregiver and the time spent providing care and quality of life, with older caregivers and those who had provided care for longer having a better quality of life score.

\section{DISCUSSION}

The profile of the elderly caregivers resembles the results of other surveys. In the present study, female caregivers with an average age of 57.51 ( \pm 11.96$)$, who were daughters, married and had a high school education predominated. The fact that women are primarily responsible for care can be explained by the historical differences between the genders. Men are seen as the main provider of income and financial expenditure, while women are responsible for the care of the household and family members, despite current changes in the labor market ${ }^{10,11}$.

Regarding the age of the participants, a profile of elderly persons caring for other elderly persons was found, corroborating findings in literature. This age group is seen as a transition phase with several changes due to aging, leading to a greater need for psychobiological attention, which is hampered by the task of caring, characterized by the performance of complex, delicate and burdensome activities ${ }^{10}$. 
In the present study, it was found that younger caregivers had lower quality of life scores than elderly caregivers. This fact can be explained by the impacts caused by care on the personal, social, professional and health life of the individual, with older caregivers having different professional and social needs than their younger counterparts, who require restructuring in all aspects of their lives when providing care, and as a result suffer a decline in quality of life.

In terms of the relationship between age and quality of life, health promotion actions involving both elderly and non-elderly groups should be considered. Despite their different characteristics and needs, both demonstrate frailty in physical and emotional health, which are involved in the task of providing care.

The choice of a family member as a caregiver usually arises from an obligation on the part of the children/spouses or financial necessity. In an integrative review carried out in 2015, the articles analyzed identified the prevalence of a family bond between the elderly person and the caregiver, and listed factors that influenced the choice of the main caregiver, such as: affective proximity, physical coexistence, cohabitation, free time and financial conditions $^{12}$.

In relation to the activity of caregiver, cohabitation with the elderly person (62.8\%) should be highlighted. Living in the same household as the elderly person generates greater daily workload when providing care, and consequently the performance of, assistance with and supervision of more tasks.

In a survey carried out at a Health School unit in São Paulo, all the family caregivers cohabited with the elderly persons with dementia. The researchers affirmed that when dividing the same residence there is a necessity to alter daily routines, based on the context of life of both the caregivers and the elderly persons. This change requires that caregivers are available to perform their role on a full-time basis and are forced to redefine their personal projects and social relationships ${ }^{6}$.

In the present study, the division of care with another person was present in $54.29 \%$ of the participants, which was similar to another study ${ }^{13}$. The division of care offers a better quality of support for the elderly through a collaboration between people arising from love, affection and concern which consecutively reduces the negative effects of stress ${ }^{14}$.

In terms of the facets of the WHOQOL-bref scale, the question referring to recreation and leisure had an average score of $32.14 \%$, which was well below half. This is related to the type of care provided, such as the hours of care, cohabitation and the division of care. Caregivers who have such characteristics tend to spend more time performing tasks of caring for the elderly, resulting in a lack of time for themselves due to the demands of care.

Although the participants had some form of disease and made continuous use of some medication, satisfaction in relation to their own health predominated $(42.86 \%)$, data which was similar to a previous study ${ }^{15}$. Studies have indicated that caregivers tend to present psychic manifestations and deterioration in physical health and the immune system, respiratory problems, heart diseases and osteoporosis $^{12,15}$. There is still no consensus on the relationship between health problems and quality of life, however, as it is considered subjective.

The Social Relationships domain, which was the best evaluated of the domains, involves issues related to sex life, personal relationships, and social support. Of these, the greatest dissatisfaction was in sex life and the greatest satisfaction was with social support.

The support provided by third parties to caregivers corroborates the fact that the division of care predominates and has a positive effect in comparison with those who do not divide care. The articulation between caregivers, family and the community is fundamental, allowing the integration of material and emotional needs, which contributes to quality of life ${ }^{16}$.

In cases where there is no support from others, the physical, mental and social health of caregivers is impaired, which can affect the quality of care provided. In order to provide a support network the issues relating to caregivers must be identified and evaluated, including their physical, emotional and financial conditions ${ }^{17}$.

The domain with the worst evaluation was Environment, which was also the case in a survey carried out with 66 caregivers of dependent elderly 
people in the state of São Paulo ${ }^{18}$. The facets with the lowest scores were recreation and leisure, health care, financial resources and means of transportation. These four issues are linked to each other, where care, often uninterrupted, and financial difficulties, impede or hinder the performance of leisure activities and satisfaction with the health service and means of transportation. Leisure, when absent or infrequent, results from the restriction of the elderly persons to their homes, requiring the constant presence of someone, usually the caregiver, to accompany them.

At the beginning of an illness there is greater integration among the family and friends of the elderly, but this characteristic tends to change as the disease progresses, so that the caregiver ends up alone in the domestic sphere of care. Lack of leisure along with home confinement leads to caregiver burden, affecting their capacities and leading to isolation, lifestyle changes, and personal dissatisfaction ${ }^{19}$.

A negative financial situation can also generate caregiver burden, resulting in difficulty with or the impossibility of (re)insertion in the labor market ${ }^{19}$. Financial difficulties are considered a strong predictor of tension for caregivers, as poor social conditions hamper the implementation of solutions to protect and elevate the health levels of the elderly ${ }^{20}$.

The care provided by caregivers can change the paradigm from one of pleasure to obligation, meaning that one's personal occupation is no longer for oneself but for another, generating daily disruption and burden ${ }^{20}$.

One limitation of the present study is the size of the sample, due to the difficulty of contacting the elderly and their caregivers, as most of the medical records were out of date, which made it difficult to select the possible participants of the research.

\section{REFERENCES}

1. Eid NT, Kairalla M, Campora F. Avaliação do grau de dependência para as atividades de vida diária de idosos. Rev Bras Clin Med. 2012;10(1):19-23.

2. Sayeg N. Como diagnosticar e tratar doença de Alzheimer. Rev Bras Med. 2012;69(12):97-109.

\section{CONCLUSION}

The present study analyzed the profile of caregivers of elderly persons with dementia and its association with quality of life, with a significant relationship found between age and total time spent providing care and quality of life. The other associations and comparisons did not exhibit significant statistical values but were sufficient to suggest the need for discussions about the variables and quality of life issues.

It is important to emphasize that nurses, in providing care for all cycles of life, are responsible for dealing with the needs of both elderly persons with dementia and their caregivers. Seeing caregivers as links of care and identifying their characteristics and care conditions as possible conditioning factors that can alter the entire structure of their lives, and consequently defining the areas that require greater care and intervention, in order to provide better quality of life for caregivers, will result in such attention being transferred to the care to be provided to the elderly, constituting an integration between elderly person-caregiver-health professional.

With regard to the other health professionals who deal with patients with dementia, it is essential to understand the reality of the care provided, so that the elderly person-caregiver binomial can be fully addressed, through the elaboration of specific strategies for the promotion, prevention and recovery of health, as both such individuals undergo restructuring in all aspects of their life.

Finally, longitudinal studies are recommended so that caregivers can be accompanied for a longer period of time and allow the thorough evaluation of the independent variables.

3. Burlá C, Camarano AA, Kanso S, Fernandes D, Nunes R. Panorama prospectivo das demências no Brasil: um enfoque demográfico. Ciênc Saúde Coletiva. 2013;18(10):2949-56. 
4. Wachholz PA, Santos RCC, Wolf LSP. Reconhecendo a sobrecarga e a qualidade de vida de cuidadores familiares de idosos frágeis. Rev Bras Geriatr Gerontol. 2013;16(3):513-26.

5. Brasil. Ministério da Previdência e Assistência Social. Política Nacional de Saúde da Pessoa Idosa. Brasília, DF: MS; 2006.

6. Bauab JP, Emmel MLG. Mudanças no cotidiano de cuidadores de idosos em processo demencial. Rev Bras Geriatr Gerontol. 2014;17(2):339-52.

7. Borghi AC, Sassá AH, Matos PCB, Decesaro MN, Marcon SS. Qualidade de vida de idosos com doença de Alzheimer e de seus cuidadores. Rev Gaúcha Enferm. 2011;32(4):751-8.

8. Novelli MMPC, Nitrini R, Caramelli P. Cuidadores de idosos com demência: perfil sociodemográfico e impacto diário. Rev Ter Ocup. 2010;20(2):139-47.

9. Tomomitsu MRSV, Perracini MR, Neri AL. Fatores associados à satisfação com a vida em idosos cuidadores e não cuidadores. Ciênc Saúde Coletiva. 2014;19(8):3429-40.

10. Araújo JS, Vidal GM, Brito FN, Gonçalves DCA, Leite DKM, Dutra CDT, et al. Perfil dos cuidadores e as dificuldades enfrentadas no cuidado ao idoso, em Ananindeua, PA. Rev Bras Geriatr Gerontol. 2013;16(1):149-58.

11. Silva SPN, Aquino CAG, Barbosa TLA, Silva CSO, Gomes LMX. A perspectiva do cuidador frente ao idoso com doença de Alzheimer. Rev Pesqui Cuid Fundam (online). 2013;5(1):3333-42.

12. Cardoso VB, Almeida JL, Costa CD, Tebaldi JB, Mattos FA. A doença de Alzheimer em idosos e consequências para cuidadores domiciliares. Memorialidades. 2015;23(24):113-49.
13. Rossi VE, Soares MA, Vilela MBT, Alves A, Oliveira MG. Perfil dos cuidadores de idosos com doença de Alzheimer de uma cidade do interior de Minas Gerais. Ciênc Praxis. 2015;8(16):27-32.

14. Pinto FNFR, Barham EJ. Bem estar psicológico: comparação entre cuidadores de idosos com e sem demência. Psicol Saúde \& Doenças. 2014;15(3):635-55.

15. Santos CF, Gutierrez BAO. Avaliação da qualidade de vida de cuidadores informais de idosos portadores da doença de Alzheimer. REME Rev Min Enferm. 2013;17(4):792-8.

16. Pereira LSM, Soares SM. Fatores que influenciam a qualidade de vida do cuidador familiar do idoso com demência. Ciênc Saúde Coletiva. 2015;20(12):3839-51.

17. Lindolpho MC, Caldas CP, Acioli S, Vargens OMC. O cuidador de idoso com demência e a política de atenção à saúde do idoso. Rev Enferm UFPE on line. 2014;8(12):4381-90.

18. Amendola F, Oliveira MAC, Alvarenga MRM. Influência do apoio social na qualidade de vida do cuidador familiar de pessoas com dependência. Rev Esc Enferm USP. 2011;45(4):884-9.

19. Pedreira LC, Oliveira AMS. Cuidadores de idosos dependentes no domicilio: mudanças nas relações familiares. Rev Bras Enferm. 2012;65(5):730-6.

20. Coelho ER, Sacerdote DS, Cardoso LTS, Barreto RMCS, Souza RC. Perfil sociodemográfico e necessidades de educação em saúde entre cuidadores de idosos em uma unidade de saúde da família em Ilhéus, Bahia, Brasil. Rev Bras Med Fam Comunidade. 2016;8(28):172-9. 